\title{
What about Platelet Function in Platelet Concentrates?
}

\author{
Michel Prudent ${ }^{1,2}$ \\ ${ }^{1}$ Laboratoire de Recherche sur les Produits Sanguins, Recherche et \\ Développement Produits, Transfusion Interrégionale CRS, \\ Epalinges, Switzerland \\ ${ }^{2}$ Centre de transfusion Sanguine, Faculté de Biologie et de Médecine, \\ University of Lausanne, Lausanne, Switzerland
}

Address for correspondence Michel Prudent, PhD, Transfusion Interrégionale CRS, Laboratoire de Recherche sur les Produits Sanguins, Route de la Corniche, 2, 1066 Epalinges, Switzerland (e-mail: Michel.prudent@itransfusion.ch).

Hämostaseologie 2020;40:500-508.

\begin{abstract}
Keywords

- monitoring

- platelet

- quality control

- transfusion medicine

Zusammenfassung

Schlüsselwörter

- Monitoring

- Thrombozyt

- Qualitätskontrolle

- Transfusionsmedizin

The characterization of platelet concentrates (PCs) in transfusion medicine has been performed with different analytical methods and platelet lesions (from biochemistry to cell biology) have been documented. In routine quality assessment and validation of manufacturing processes of PCs for transfusion purposes, only basic parameters are monitored and the platelet functions are not included. However, PCs undergo several manipulations during the processing and the basic parameters do not provide sensitive analyses to properly picture out the impact of the blood component preparation and storage on platelets. To improve the transfusion supply chain and the platelet functionalities, additional parameters should be used. The present short review will focus on the different techniques to monitor ex vivo platelet lesions from phenotype characterization to advanced omic analyses. Then, the opportunities to use these methods in quality control, process validation, development, and research will be discussed. Functional markers should be considered because they would be an advantage for the future developments in transfusion medicine.

Die Charakterisierung von Thrombozytenkonzentraten (TK) wird in der Transfusionsmedizin mithilfe von verschiedenen analytischen Methoden durchgeführt und dabei können Thrombozytenläsionen (von der biochemischen bis zur zellulären Ebene) festgestellt werden. In der routinemässigen Qualitätsprüfung und bei der Validierung von Herstellungsverfahren von TK für Transfusionszwecke werden nur grundlegende Parameter überprüft, allerdings nicht die Thrombozytenfunktion. TK erfahren jedoch mehrere Bearbeitungsschritte während der Herstellung und die Analyze der Standardparameter ist nicht ausreichend um den Einfluss der Blutkomponentenherstellung und der Lagerung auf Thrombozyten zu erfassen. Um die Transfusionsversorgungskette und die Funktionalität der Thrombozyten zu verbessern, sollten zusätzliche Parameter berücksichtigt werden. In diesem kurzen Review liegt der Fokus auf verschiedene Techniken um ex vivo Thrombozytenläsionen, durch Phänotypcharakterisierung bis hin zu modernsten Omik-Analysen, aufzuzeigen. Anschliessend wird der Nutzen dieser Methoden für Qualitätskontrolle, Prozessvalidierung, Entwicklung und Forschung diskutiert. Funktionsmarker sollten berücksichtigt werden, da sie einen Vorteil für zukünftige Entwicklungen in der Transfusionsmedizin darstellen würden.
\end{abstract}

received

May 15, 2020

accepted after revision

June 29, 2020 (c) 2020 Georg Thieme Verlag KG Stuttgart · New York
DOI https://doi.org/

10.1055/a-1210-3229.

ISSN 0720-9355. 


\section{Introduction}

It appears trivial nowadays to order a bag of platelets for transfusion purposes. Nevertheless, the products available today are the consequences of several developments in blood component processes. The ex vivo conditions (i.e., when the platelets are outside the human body and the physiological conditions) are obviously different than the in vivo conditions; platelets are concentrated $\left(600-2,000 \times 10^{9}\right.$ cells/L against $150-400 \times 10^{9}$ cells/L in vivo), the plasma surrounding them can be diluted to around 30 to $40 \%$ by storage solutions, and they are sequestrated in a gas-permeable plastic bag at $22^{\circ} \mathrm{C}$. During this ex vivo journey platelets develop different lesions. ${ }^{1,2}$

Platelet concentrates (PCs) and the processes behind have to meet several criteria defined by regulation agencies based on guidelines. ${ }^{3}$ Beyond the donor qualification, volume, concentration of platelets, residual cell contaminations, $\mathrm{pH}$, temperature, and so on follow different directives. Hence, these conditions and controls should guarantee that the platelets are still functional for transfusion even after 7 days of storage (or 5 days unless bacterial detection or pathogen inactivation methods are applied).

However, platelet functions are not taken into account here, neither in validation of processes nor in quality control, whereas several research studies include advanced analyses in the study of platelets. Do the cited parameters power enough to guarantee the platelet quality or more precisely their functional properties (indeed quality could also refer to quality management, which is another subject)? Are they power enough to develop new processing or storage strategies able to improve the platelet transfusion efficiency? The quantification of ex vivo modifications is of primary importance to evaluate the impact of blood component preparation from the donors to the patients. This is even more important considering that the patients have different needs. PCs are used in preventive treatments (prophylactic use) to maintain platelet count and to prevent bleeding (which is the case in hemato-oncology), and in curative treatments to stop hemorrhage (e.g. surgery bleeding in patients under antagonists of thrombocyte aggregation).

The present concise review will therefore focus on the in vitro parameters that are used in the characterization of PCs, and the opportunities for the monitoring and the development of these blood products.

\section{Preparation of Platelet Concentrates}

Before the transfusion, platelets have to be extracted from blood and stored. They can be harvested by apheresis methods, where only the targeted cells (platelets here) are selected, producing a bag containing one to three units ready for further processing. From whole blood, two processes are feasible: the platelet-rich plasma and buffy-coat methods. A soft-spin centrifugation of the whole blood is used to produce platelet-rich plasma. Another centrifugation step is then required to concentrate the platelets and a PC is obtained by the pooling of units from several donations. In the case of the buffy-coat method, a hard-spin centrifugation is applied and platelets are concentrated within the buffy-coat layer. Buffy-coat units from several donations are pooled together and centrifuged again. Leukocytes are depleted by filtration. The platelets can remain in $100 \%$ plasma or prepared in different platelet additive solutions, ${ }^{4}$ with 30 to $40 \%$ of plasma.

PCs can be pathogen-inactivated depending on regulations. The principle is to modify genetic materials to avoid pathogen replication. It is based on photo- or photochemical treatments. Three technologies are available: the Intercept blood system using a combination of ultraviolet (UV)-A light and amotosalen (Cerus Corporation, United States; commercially available), the Mirasol pathogen reduction technology system (Terumo BCT, United States; commercially available) using a combination of UV light and riboflavin, and the Theraflex UV-platelets using UV-C light only (Marcopharma, France; phase III clinical trial). ${ }^{5,6}$

PCs are stored between 20 and $24^{\circ} \mathrm{C}$ under agitation. The storage is limited to 5 days postdonation unless bacterial detection or pathogen-inactivation treatments are applied, in that case, storage is 7 days. Other products such as plasmaremoved PCs or cryopreserved platelets can be prepared. It has to be noticed that cold platelets (i.e., stored at $4^{\circ} \mathrm{C}$ ) are under evaluations but are not in routine use. ${ }^{7-10}$ This type of storage could be a good opportunity for the treatment of bleeding patients. Moreover, it can reduce the pressure on the blood supply by increasing the storage period and reducing the risk of bacterial contamination in countries where pathogen-inactivation treatments are not adopted. ${ }^{11}$

All these steps (in addition to the donor's characteristics) influence the storage of the platelets: the centrifugation steps and the contact to plastic can activate the cells, the final platelet concentration can play a role on the metabolism, and the pathogen inactivation modifies some of the properties. To control the processing, several criteria have to be met. The maximum residual cell contaminations have to be below $1 \times 10^{6}$ leucocytes/PC and $4 \times 10^{6}$ red blood cells/mL, the concentration of platelets has to remain higher than $2.0 \times 10^{11} /$ unit $\left(2.4 \times 10^{11} /\right.$ unit in Switzerland and other countries) as recommended by the European directives, ${ }^{3}$ and the $\mathrm{pH}$ has to be higher than 6.4 until the end of the storage period. The in-process control and monitoring control are listed in -Table 1 . These parameters are used for the validations of manufacturing processes too.

\section{Platelet Lesions}

Any step from the donation to the transfusion has an impact on the quality of the PC. ${ }^{1,2,4,6,12,13}$ As mentioned before there are criteria that have to be met from visual inspection to cell count and $\mathrm{pH}$. The ex vivo properties have been explored visually (presence of aggregates, swirling score) and investigated by in vitro assays (including platelet phenotype and functions) and more recently by omic approaches ${ }^{14-16}$ (i.e., metabolomics, ${ }^{17,18}$ transcriptomics, ${ }^{19}$ or proteomics ${ }^{20}$ ).

\section{Phenotype of Stored Platelets}

Phenotype is usually characterized by flow cytometry. The majority of the phenotype includes surface marker quantification such as glycoproteins (GPs) that provides information 
Table 1 Quality control parameters in Switzerland

\begin{tabular}{|l|l|l|l|}
\hline Parameters & Criteria & Process & Frequency \\
\hline Visual control & Color, aggregates, swirling & Before processing & All units \\
\hline Volume & $>150 \mathrm{~mL}$ & After pathogen inactivation & $1 \%$ of the production/year \\
\hline Platelet content & $\geq 2.5 \times 10^{11} /$ unit & Before pathogen inactivation & $10 \mathrm{bags} / \mathrm{mo}$ \\
\hline & $\geq 2.4 \times 10^{11} /$ unit & After pathogen inactivation & $10 \mathrm{bags} / \mathrm{mo}$ \\
\hline Leukocyte content & $<1 \times 10^{6} /$ unit & Before pathogen inactivation & $10 \mathrm{bags} / \mathrm{mo}$ \\
\hline Red blood cell concentration & $<4 \times 10^{6} / \mathrm{mL}$ & Before pathogen inactivation & $10 \mathrm{bags} / \mathrm{mo}$ \\
\hline $\mathrm{pH}$ & $>6.4$ at $22^{\circ} \mathrm{C}$ & From 5 to 7 days of storage & $1 \%$ of the production/year \\
\hline
\end{tabular}

on the modification of receptors. These modifications are spontaneous and are not the consequences of specific stimulations. GPIb (also called CD42b, part of the von Willebrand receptor) decreases during the storage until day 7 postdonation and its expression is influenced by treatments such as pathogen inactivation. ${ }^{21-25}$ Indeed, amotosalen/UV-A treatment induces the desialylation and cleavage of this receptor (increase of glycocalicin). ${ }^{24}$ GPIIbIIIa (integrin $\alpha I I b ß I I I$, fibrinogen receptor), GPIaIIa (integrin $\alpha 2 \beta 1$, collagen receptor), and GPVI (immunoglobulin-like transmembrane protein, collagen receptor) remain stable through the storage. ${ }^{23}$ The activated form of $\alpha$ IIbßIII can be quantified using binding affinity to procaspase-activating compound 1 (PAC-1). An increase activation of this GP has been reported following pathogen-inactivation procedures (higher in the case of riboflavin/UV light). ${ }^{21,22}$ of note, the treatments used do not provide the same levels of activation.

Other markers can be monitored such as the expression of p-selectin (CD62P), a hallmark of platelet activation, and the exposure of phosphatidylserine (PS), a marker of pre-apoptosis. CD62P is sensitive and it can be expressed by centrifugation steps or pathogen-inactivation techniques. It increases after processing steps as well during the storage. ${ }^{21-23,25-27}$ As for the PS exposure (usually quantified by binding to annexin V), the percentages increase and the effect is even exacerbated by the pathogen inactivation. It has to be noticed that the sample preparation influences the results. Hechler et al reported no effect of pathogen inactivation with amotosalen/UV-A on these two markers compared with untreated PCs. ${ }^{23}$

Soluble GP can also be quantified in the supernatant of PCs (using ELISA kit). Soluble GPV was found to increase during the storage in different additive solutions and in plasma, and it was correlated to CD62P, hypotonic shock response (HSR), and lactate concentration. ${ }^{28}$ It was proposed as an ex vivo activation marker.

Other membrane and cytosolic proteins can be modified too (see the Proteomics section below). ${ }^{12,15}$ Regarding specific pathways and apoptotic events in particular, overexpression of Bak protein and cleaved caspase-3 were observed after amotosalen/UV-A treatment (due to UV illumination). ${ }^{24}$ Similar data were obtained for the treatment with riboflavin/UV. ${ }^{29,30}$

\section{Function of Stored Platelets}

Because the role of platelets is to react to stimuli, the functions of platelets are challenged using different agonists.
Like phenotype analyses, the platelet reactivity can be monitored by flow cytometry. Following adenosine diphosphate (ADP) stimulation, decreases of alIbßIII activation and pselectin expression were clearly reported since the beginning of the storage. ${ }^{27}$ Such results suggest a functional defect due to weak stimulation. The hypothesis is a desensitization of the ADP receptors because of previous exposition to ADP. ${ }^{27,31,32}$ These investigations enable scientists to monitor the reactivity of the platelets to activation and to investigate different cellular pathways.

Collagen- and thrombin-activated (COAT) platelets are another functional characteristic of platelets. ${ }^{33,34}$ They are a subpopulation of platelets induced by coactivation with collagen and thrombin, and typically represent $30 \%$ of circulating platelets in healthy individuals. ${ }^{35-37}$ They exhibit particular procoagulant properties, one of the major roles of platelets besides aggregation. They are characterized by a high and sustain level of cytosolic calcium, the exposure of PS, and are PAC-1 negative (inactivation of the $\alpha$ IIbßIII). In in vitro assays, the percentage of COAT is quantified by PS exposure after the dual activation with convulxin and thrombin. In buffy-coatderived PCs the percentages of COAT platelets were decreased from more than $30 \%$ to less than $10 \% .{ }^{27}$ By consequence, they were reported to be present at a lower level in PCs than in human. Decreases of COAT population were also observed to different extent in buffy-coat-derived PCs ${ }^{38}$ and PCs from apheresis. ${ }^{39}$ On the contrary, Alberio and colleagues showed that the COAT properties were increased in cryopreserved platelets. ${ }^{40}$ Indeed, the mean percentage of COAT platelets was $56.4 \%$, which is far higher than what was observed in conventional PCs. Nevertheless, it is obvious to mention that the platelet preparation was different; platelets were kept in plasma and gamma-irradiated.

Another method of evaluating platelet function is aggregometry, which is used both in diagnosis and in research on platelets. The response is monitored in function of different agonists, such as collagen, thrombin receptor activating peptide (TRAP), ADP, arachidonic acid, epinephrine, or different combinations. Usually the response decreases in function of the storage time and it is influenced by the platelet additive solution used. ${ }^{4}$ The use of a couple of agonists to activate platelets (e.g., epinephrine and ADP or collagen) in vitro induces a higher response than single activation. ${ }^{22}$ Aggregometry allows us to probe different pathways in platelet aggregation, which is of interest in the preparation of PCs. 
The different centrifugation steps or the pathogen inactivation modify the response to agonists, which might provide information on the impacted molecular pathways.

Thromboelastography (TEG) or rotational thromboelastometry (ROTEM) are point-of-care tests used in the clinic to assess hemostatic properties of platelets in whole blood samples. They provide general information on the clot formation and the in vivo hemostasis, which requires whole blood samples. A few studies have reconstituted blood using 1:1:1 or $4: 4: 1$ ratio of red blood cells, plasma, and platelets, ${ }^{41,42}$ to investigate the hemostatic properties of blood products. This approach can be of interest to study the effect of processing or storage in stored platelets in a context close to in vivo and provides information on the hemostatic properties of PCs. Indeed, some conditions (cold storage, for instance) could change these properties. These methods could therefore evaluate the potential impacts of the PC preparation and storage on the transfused patients. It is also important to notice here that the supernatant of PCs, which contain microvesicles and other biological response modifiers, could participate in the hemostatic properties evaluated using TEG or ROTEM. Therefore, the experimental design has to include both the cells and the supernatant.

In the diverse assays available, HSR is a convenient test. It consists of monitoring the capacity of platelets to resist a hypotonic stress by adding water to the sample. The percentage of HSR slightly decreases during the storage, which is further exacerbated by pathogen-inactivation treatments. ${ }^{21,22}$ It negatively correlates to the PS exposure in conventional storage. ${ }^{22} \mathrm{HSR}$ is an easy-to-use technique and it might be taken into account to assess the level of lesions at the cellular level.

Another interesting approach is the use of light scattering to monitor platelet shape change and microparticle content following temperature cycling. ${ }^{43,44} \mathrm{~A}$ score can be obtained (including platelet shape as well as microparticle count), which represents the quality of the PCs. The idea of such type of control could be the elimination of "poor" PCs or the distribution of them in function of the score. However, the threshold definition is blood center-dependent and difficult to determine.

Thrombin generation that measures the capacity of platelet to produce thrombin provides data on the functionality. A decrease was reported through the storage. ${ }^{38}$

\section{Metabolic Status}

Studies of platelet metabolism and blood gas exchange are useful in the context of transfusion medicine. They are usually extracellular quantifications that provide information on the behavior of ex vivo cell aging. As expected in such close systems, a consumption of glucose and a production of lactate are observed. This production has a direct impact on the $\mathrm{pH}$, which is one of the parameters tested in the routine quality controls. Intracellular concentrations of adenosine triphosphate (ATP) slightly decrease during the storage. ${ }^{26} \mathrm{As}$ for ADP (important for platelet stimulation), the decrease is followed by a plateau after 4 days of storage showing different trends (see the Metabolomics section for more details). ${ }^{18}$
The consumption of glucose, and by extension the metabolic activity of platelets during the storage, is influenced by the type of additive solutions used and by the processing. Indeed, the absence of $\mathrm{K}^{+}$and $\mathrm{Mg}^{2+}$ in the additive solution participates to the increase in glucose consumption, ${ }^{22,45}$ as well as the use of UV-B illumination in the riboflavin/UV treatment. ${ }^{21,22}$ ATP levels were reported lower in riboflavin/UV-treated platelets at day 8 compared with untreated PCs. ${ }^{26}$ An overconsumption of glucose can exhaust the metabolite activity and negatively affect the storage by a diminution of available cell energy and antioxidant defenses, and a decrease of $\mathrm{pH}$ because of lactate production.

\section{Advanced Analyses}

Once phenotypic or functional platelet lesions are identified, it is sometimes difficult to understand the reasons and evaluate the clinical impact. It is therefore necessary to go deeper into the platelets biology and biochemistry. This step is not directly useful for quality control in transfusion medicine but necessary to carry out hypothesis-driven research and development strategies. It requires all the methods involved in research laboratories in biology and biochemistry. The next paragraph will focus on examples in omic sciences.

\section{Metabolomics}

The omic approaches based on mass spectrometry have enabled the analysis of a huge amount of metabolites present in a sample. Although they require careful sample preparations and not all metabolites can be quantified by such an approach (we can mention here glutathione or other thiol derivatives that require derivatization because of oxidation injuries during the ionization process), studies on relative quantifications have been performed during storage and in function of pathogen-inactivation treatments.

Paglia et al described the evolution of the metabolism (mainly carbon-centered and energy metabolism) during the storage. ${ }^{18}$ Three different metabolic phenotypes were deduced, with shifts from one regime to another one after day 3 and day 6. From days 0 to 3 , the main activity was found in the glycolysis, the pentose phosphate pathway, and the glutathione synthesis. A lower activity was reported in a tricarboxylic acid cycle and oxidative phosphorylation. Then, from days 4 to 6 , the two last pathways were reactivated, and purine metabolism was used to recycle hypoxanthine. Finally, from days 7 to 10 (beyond the storage duration defined by regulation), metabolites started to accumulate without recirculation.

When pathogen-inactivation treatments are included in the investigation, three types of metabolite evolution were reported: effect of storage only, storage effect exacerbated by pathogen inactivation, and direct effect of the treatment. Hence, in the case of amotosalen/UVA-treated PCs, all these alterations were observed, particularly oxidative damages. ${ }^{17}$ This was particularly true in the purine pathway where urate was oxidized to allantoin following the photochemical treatment. It is one of the proofs of the oxidative damages induced by pathogen-inactivation treatments. ${ }^{17,46,47}$ 
Lipidomics is considered as a subcategory of metabolomics, even though different sample preparations and analytical setup are used. Lipids are not only important in membrane composition but also in signaling and platelet activation. During the storage, the platelet lipidome is modified. This topic was recently reviewed by Johnson and colleagues. ${ }^{48}$

\section{Proteomics}

Protein platelet analyses using a proteomic approach have been performed for almost two decades. ${ }^{15,49}$ It enables the identification of the proteome of platelets under resting or activated conditions. ${ }^{50-56}$ More than 3,800 proteins were identified by Burkhart et al ${ }^{52}$ and even 4,100 in apheresis PCs by Aloui et al. ${ }^{55}$

Beyond the identification of proteins, proteomics provide information on the pathways involved or affected in function of the tested conditions. As a few examples, García et al identified the upregulation of Dock-2 protein and the phosphorylation of a regulator of $G$ protein signaling in TRAP-activated platelets. ${ }^{57}$ Qureshi et al deeply studied the phosphoproteome (i.e., the group of proteins containing phosphorylation modifications) with a focus on the integrin $\alpha$ IIbßIII network. ${ }^{51}$ More recently, Beck et al applied a temporal quantification to analyze the phosphoproteome evolution in response to ADP and ADP plus Iloprost. ${ }^{58}$ This approach enabled them to identify and quantify early response (within 10 seconds following the treatment), medium response (30 seconds), and late response (60 seconds). The careful analysis showed a modulation of ADP-induced phosphorylation by Iloprost and the identification of reversible sites in view of monitoring activation states for the clinic.

In transfusion medicine, the platelet proteome is moderately modified during the storage with a low number of differently expressed proteins. Identified proteins are linked to platelet activation, cytoskeletal reorganization, vesicle trafficking, and apoptosis pathways. The pathogen-inactivation treatments moderately impact the proteome. ${ }^{20}$ In the case of riboflavin/UV treatment that showed oxidative lesions, protein carbonylations were reported once the treatment applied ${ }^{47}$ and 17 proteins were identified as irreversibly oxidized. ${ }^{54}$ These proteins were involved in platelet shape change and aggregation pathways.

The protein identification is important but the weak impact on the overall proteome in PCs hardly explains the phenotype and functional defects observed at the cellular level (described in the previous sections). Advanced proteomics has been required to study protein functions, posttranslational modifications (oxidation, phosphorylation, ...), protein signaling, and so forth. Of particular interest in transfusion medicine and blood processing is the study of phosphorylation. Schubert et al discovered that a phosphorylation form of a kinase (p38MAPK) was overexpressed following the treatment with riboflavin/UV. ${ }^{59}$ Stivala et al confirmed this observation in the case of amotosalen/UVA treatment. ${ }^{24}$ This protein plays a key role in the regulation of platelet function. Moreover, such regulations are in crosstalk to oxidative mechanisms such as reactive oxygen species and cysteine oxidation. ${ }^{60}$ Cysteine oxidation was reported to be linked to $\alpha$ IIbßIII activation in PC treated with UV-C light. ${ }^{61}$ We recently identified reversible cysteine oxidation in this integrin following amotosalen/UVA treatment (Sonego G et al., under revision).

The omic investigations have been useful for the understanding of molecular pathways and the various responses to stimuli. Recently, there was a shift from the proteome discovery to quantitative physiological and pathological variations. ${ }^{55}$ Nevertheless, these is still some challenges in sample preparation (washing, inhibitors, resting or activated platelets), standardization, and complex workflow transfer in routine and low abundant and highly modified proteins.

\section{Correlation to In Vivo Data}

Despite all the available methods, it is sometimes difficult to picture out the whole clinical impact that also depends on the patients' status. The correlations to clinical outcomes are important for choosing the right analytical approach. Several parameters were reported to correlate to recovery or survival such as morphology and swirling, p-selectin, lactate, or HSR. ${ }^{63}$ Recently, van der Meer and colleagues investigated correlations between in vitro assays and the corrected-count increment $(\mathrm{CCI})$ at 1 hour in hemato-oncology patients. ${ }^{64}$ The CCI enables the evaluation of the increase in circulating platelets after a transfusion, corrected for the body surface and the dose. It is indicative of a good recirculation of the transfused platelets. They found that some assays correlate to $\mathrm{CCI}$, such as the p-selectin expression and PS exposure. The combination of these markers to lactate concentration (in vitro rating score) improved the correlation. Moreover, the platelet responsiveness after stimulation with TRAP provides a correlation to CCI with a Spearman's coefficient of 0.57 and a $p$-value of 0.0001 (for the mean responsiveness). Such studies provide the required data to select the right parameters. Functional assays should be more suitable to link in vitro parameters to clinical outcomes.

Another important marker is the bleeding score, ${ }^{65}$ to which the $\mathrm{CCI}$ is a poor surrogate marker. ${ }^{66}$ It is classified in four grades according to the World Health Organization, 4 being the worst case. Grades 3 and 4 are clinically relevant and grade 2 could be considered a surrogate outcome. ${ }^{65}$ TEG was shown to correlate to grade 2 bleeding. Different parameters can be extracted from a TEG, such as the maximum amplitude, the reaction time, or the $\alpha$ angle. In thrombocytopenic patients, only the $\alpha$ angle was reported to correlate to bleeding with a $p$-value of $0.003 .^{67}$

These clinical data are important to find correlations and drive developments. Nevertheless, it is difficult to carry out clinical trials to evaluate the efficacy of platelet transfusions in transfusion medicine. In the absence of clinical studies, it is almost impossible to evaluate the changes and find these correlations. A recent committee report was published on this subject. 68

Finally, markers could be also influenced by the pathological situation. The needs in term of platelet support are different in preventive and curative treatments. In hematooncology, the aim is to maintain a high enough level of platelets and the $\mathrm{CCI}$ is a good indicator to follow. However, 
the $\mathrm{CCI}$ does not provide information on the hemostatic efficiency of transfused platelets. In curative treatments, where hemostatic support is compulsory, other indicators should be used.

\section{What to Do?}

The various techniques and results briefly presented here provide opportunities to better characterize platelets for transfusion purposes. They bring different levels of information with different levels of complexity. None of them is applicable to all cases in transfusion medicine.

All these assays provide a lot of information on platelets and their ability to response to various stimuli. In function of the molecules used (activator or inhibitor), different biochemical pathways can be tested and challenged. It might provide information regarding the part of the function that can be modified by the process or the storage. Once identified, corrective strategies might be evaluated. This is particularly useful for the development of new strategies in transfusion medicine and patient health care. Particularly, they allow to evaluate the impact of a procedure or another one and to add information for process development for instance.

\section{Parameters in Blood Processing}

In quality control and in-process control issues, the assays have to be affordable and compatible with the production line. For these reasons, basic characterizations such as visual inspection or diverse cell counts are the primary choices. The visual inspection can advise the operator to a potential problem with the bags (or with the donation since the swirling score might depend on individual factors) in the case of aggregates or absence of swirling. They are direct proofs of issues with the platelets on shape change and platelet interactions. In spite of these controls, the platelets can be activated or in a preapoptotic state. As for the $\mathrm{pH}$, the requirement is usually reached even with PCs for more than a week of storage or if the agitation was stopped for more than a day. Noninvasive methods (or without any risk of contamination) would be the grail and would avoid to throw out blood products. In absence of such methods, a small volume is withdrawn into a satellite bag and other PCs are selected for control purposes and not transfused. In monthly controls, phenotype and functional assays might be included to propose an advanced monitoring of the production. Additional controls are present during the processing (traceability, intermediate count, ...) but are out of the scope of the present review.

In process development and validation (e.g., test of new bags, novel centrifugation steps, resting times, inactivation techniques, and so on), additional parameters should be included such as platelet functions. Nowadays, only a few parameters are included (bag volume, platelet count, $\mathrm{pH}$, and residual cell contamination; see - Table 1). However, it would be important to consider the function of platelets. Indeed, several processes activate platelets, which is not visible with the visual inspection and the cell counts. The addition of phenotype characterizations and functional assays will help to provide platelets of better quality with lower levels of lesions. Nevertheless, the definition of the quality is still not clear. Does it mean "no difference compared to conventional conditions" or "equivalent to physiological functions"? In this context, it is important to notice that the modifications of platelet properties are not all irreversible. Some of them can be rescued in vivo once transfused (especially the defect linked to metabolism and the morphology). These reversible lesions can therefore be considered as minor whereas the irreversible ones have to be considered as major. Finally, the answer can depend on patient status, where needs can be different in hematooncology and bleeding patients (as already mentioned).

Advanced analyses are "restricted" to research laboratories and in some cases clinical investigations. They are not applicable in routine because of the level of expertise required and the cost of the analyses. However, they are the cornerstone to pursue investigations and find strategies to develop blood products. It is true to define new markers in process development and quality control, and to correlate and investigate the clinical impact on patients to particular processing and storage conditions. These types of analyses should be included in clinical trials as much as possible.

\section{Investigation of In Vivo Function of Transfused Platelet Concentrates}

The final and decisive evaluations of PCs are based on in vivo survival and recovery, which is not systematically required (modifications of filter types or resting steps does not require in vivo studies for example). Labeled platelets are used for the quantification.

Cellular survival and recovery as well as cell functions are of primary importance to properly assess the benefit of a treatment. These experiments have been based on radioactive tracers $\left({ }^{111} \mathrm{In}\right.$ or ${ }^{51} \mathrm{Cr}$ ) to label cells and investigate the in vivo behaviors. This approach is cumbersome, requires particular techniques, and is available only in specific institutions. The use of biotin can safely replace the radioactive tracers (as already shown in red blood cells in human subjects ${ }^{69,70}$ ). Transfusion of biotinylated cells to patients has already been done using red blood cells notably by Mock and colleagues since 1999. ${ }^{71}$ Biotinylation of platelets is feasible, ${ }^{72,73}$ and recently research groups have worked and developed methods on it. ${ }^{74,75}$

The infusion of labeled platelets in healthy volunteers and patients enable to study not only the recovery and the recirculation but also the in vivo function of platelets. Indeed, biotinylated platelets can be specifically detected by flow cytometry for quantification. In addition, this population can be studied in more detail to quantify the phenotype (spontaneous markers) as well as the platelet functions. For instance, after the in vitro activation with an agonist, it is possible to detect the level of activation of this labeled population.

The information on platelet functions obtained with labeled platelets should be included to properly assess the properties of transfused platelets. Therefore, it will provide information on platelets in function of patients' status to adapt transfusion practices as well as information on correlation data to drive the selection of in vitro monitoring parameters. 


\section{Conclusions}

The characteristics of PCs are influenced by almost all the steps from the donors to the patients: donors' characteristics, collection, processing, storage conditions (removing of plasma, cryopreservation, storage at $4^{\circ} \mathrm{C}, \ldots$ ). The general trends of ex vivo aging of platelets are equivalent but differences in amplitude and kinetics are found in function of the previously cited parameters.

The criteria used today enable to secure the supply chain with adapted methods and at costs that are affordable by the blood banks and the health care systems. However, there is still room for improvement and it is critical to develop new methods of collection, processing, and storage to extend platelet storage time and quality, and to include new metrics. ${ }^{76}$ Currently, there are three issues to consider: (1) probe and improve platelet functionalities because function must become part of the quality assessment, (2) reduce cost, risks, and secure platelet availability for transfusion, (3) get out of the "one-size-fits-all" model (defined on circulating platelet count paradigm) regarding the patients' needs.

All the analyses regarding platelet phenotypes and functions, including advanced analyses, are of particular interest and of particular need to (1) drive the developments and improvements in PC production procedures (e.g., resting time or other filtrations, evaluation of kits, special products such as washed PCs, and so on) and the storage conditions (additive solution, cold, and cryopreservation, for instance) and (2) understand clinical effects: correlation to in vivo data, correlation and causality between the tryptic: donors-products-patients.

Functional markers should definitively be considered and included in recommendations. We have all the techniques available to get out of empirical developments and to pursue hypothesis-driven research and development. Beyond these developments and controls, there is issue on cost, logistics, and so on, but the patients' benefit should be prioritized first.

\section{Conflict of Interest}

Dr. Prudent reports grants and nonfinancial support from New Health Sciences, nonfinancial support from Terumo BCT, outside the submitted work. In addition, Dr. Prudent has a patent Test de contrôle de qualité pour vérifier l'exécution des traitements d'inactivation des pathogènes et des cellules ciblées dans le sang, les produits dérivés du sang et produits cosmétiques pending.

\section{Acknowledgment}

M.P. thanks E. Längst for the German translation and Dr. N. Dögnitz and the collaborators from the R\&D for discussions.

\section{References}

1 Shrivastava M. The platelet storage lesion. Transfus Apheresis Sci 2009;41(02):105-113

2 Tissot JD, Bardyn M, Sonego G, Abonnenc M, Prudent M. The storage lesions: from past to future. Transfus Clin Biol 2017;24 (03):277-284
3 EDQM. Guide to the Preparation, Use and Quality Assurance of Blood Components. 19th ed. Strasbourg: European Directorate for the Quality of Medicines \& HealthCare, Council of Europe; 2017

4 van der Meer PF, de Korte D. Platelet additive solutions: a review of the latest developments and their clinical implications. Transfus Med Hemother 2018;45(02):98-102

5 Seltsam A. Pathogen inactivation of cellular blood products-an additional safety layer in transfusion medicine. Front Med (Lausanne) 2017;4:219

6 Schubert P, Johnson L, Marks DC, Devine DV. Ultraviolet-based pathogen inactivation systems: untangling the molecular targets activated in platelets. Front Med (Lausanne) 2018;5:129

7 Johnson L, Tan S, Wood B, Davis A, Marks DC. Refrigeration and cryopreservation of platelets differentially affect platelet metabolism and function: a comparison with conventional platelet storage conditions. Transfusion 2016;56(07):1807-1818

8 Braathen H, Sivertsen J, Lunde THF, et al. In vitro quality and platelet function of cold and delayed cold storage of apheresis platelet concentrates in platelet additive solution for 21 days. Transfusion 2019;59(08):2652-2661

9 Strandenes G, Kristoffersen EK, Bjerkvig CK, et al. Cold-stored apheresis platelets in treatment of postoperative bleeding in cardiothoracic surgery. Transfusion 2016;56:16A-16A

10 Corley JB, Messenger JM, Cheser JL, et al. Implementation of cold stored platelets for combat trauma resuscitation. Transfusion 2016;56:16A-17A

11 Cap AP. Platelet storage: a license to chill!. Transfusion 2016;56 (01):13-16

12 Feys HB, Van Aelst B, Compernolle V. Biomolecular consequences of platelet pathogen inactivation methods. Transfus Med Rev 2019;33(01):29-34

13 Garraud O, Tissot J-D. Blood and blood components: from similarities to differences. Front Med (Lausanne) 2018;5(84):84

14 Lion N, Tissot JD, Prudent M. What can omics bring to transfusion? Blood Transfus 2016;14(Suppl 1):INV-07

15 Prudent M, Tissot JD, Lion N. Proteomics of blood and derived products: what's next? Expert Rev Proteomics 2011;8(06): 717-737

16 Nemkov T, Hansen KC, Dumont LJ, D’Alessandro A. Metabolomics in transfusion medicine. Transfusion 2016;56(04):980-993

17 Abonnenc M, Crettaz D, Marvin L, et al. Metabolomic profiling highlights oxidative damages in platelet concentrates treated for pathogen inactivation and shows protective role of urate. Metabolomics 2016;12(12):188

18 Paglia G, Sigurjónsson OE, Rolfsson Ó, et al. Comprehensive metabolomic study of platelets reveals the expression of discrete metabolic phenotypes during storage. Transfusion 2014;54(11): 2911-2923

19 Osman A, Hitzler WE, Ameur A, Provost P. Differential expression analysis by RNA-Seq reveals perturbations in the platelet mRNA transcriptome triggered by pathogen reduction systems. PLoS One 2015;10(07):e0133070

20 Prudent M, D’Alessandro A, Cazenave J-P, et al. Proteome changes in platelets after pathogen inactivation-an interlaboratory consensus. Transfus Med Rev 2014;28(02):72-83

21 Abonnenc M, Sonego G, Crettaz D, et al. In vitro study of platelet function confirms the contribution of the ultraviolet $B$ (UVB) radiation in the lesions observed in riboflavin/UVB-treated platelet concentrates. Transfusion 2015;55(09):2219-2230

22 Abonnenc M, Crettaz D, Sonego G, Escolar G, Tissot JD, Prudent M. Towards the understanding of the UV light, riboflavin and additive solution contributions to the in vitro lesions observed in Mirasol@-treated platelets. Transfus Clin Biol 2019;26(04): 209-216

23 Hechler B, Ohlmann P, Chafey P, et al. Preserved functional and biochemical characteristics of platelet components prepared with amotosalen and ultraviolet A for pathogen inactivation. Transfusion 2013;53(06):1187-1200 
24 Stivala S, Gobbato S, Infanti L, et al. Amotosalen/ultraviolet A pathogen inactivation technology reduces platelet activatability, induces apoptosis and accelerates clearance. Haematologica 2017;102(10):1650-1660

25 Van Aelst B, Devloo R, Vandekerckhove P, Compernolle V, Feys HB. Ultraviolet $C$ light pathogen inactivation treatment of platelet concentrates preserves integrin activation but affects thrombus formation kinetics on collagen in vitro. Transfusion 2015;55(10): 2404-2414

26 Picker SM, Tauszig ME, Gathof BS. Cell quality of apheresisderived platelets treated with riboflavin-ultraviolet light after resuspension in platelet additive solution. Transfusion 2012;52 (03):510-516

27 Bertaggia Calderara D, Crettaz D, Aliotta A, et al. Generation of procoagulant collagen- and thrombin-activated platelets in platelet concentrates derived from buffy coat: the role of processing, pathogen inactivation, and storage. Transfusion 2018;58(10): 2395-2406

28 Kiminkinen LK, Krusius T, Javela KM. Evaluation of soluble glycoprotein $\mathrm{V}$ as an in vitro quality marker for platelet concentrates: a correlation study between in vitro platelet quality markers and the effect of storage medium. Vox Sang 2016;111 (02):120-126

29 Chen Z, Schubert P, Culibrk B, Devine DV. p38MAPK is involved in apoptosis development in apheresis platelet concentrates after riboflavin and ultraviolet light treatment. Transfusion 2015;55 (04):848-857

30 Reid S, Johnson L, Woodland N, Marks DC. Pathogen reduction treatment of buffy coat platelet concentrates in additive solution induces proapoptotic signaling. Transfusion 2012;52 (10):2094-2103

31 Keuren JF, Cauwenberghs S, Heeremans J, de Kort W, Heemskerk JW, Curvers J. Platelet ADP response deteriorates in synthetic storage media. Transfusion 2006;46(02):204-212

32 Hardy AR, Conley PB, Luo J, Benovic JL, Poole AW, Mundell SJ. P2Y1 and P2Y12 receptors for ADP desensitize by distinct kinasedependent mechanisms. Blood 2005;105(09):3552-3560

33 Mazepa M, Hoffman M, Monroe D. Superactivated platelets: thrombus regulators, thrombin generators, and potential clinical targets. Arterioscler Thromb Vasc Biol 2013;33(08):1747-1752

34 Heemskerk JW, Mattheij NJ, Cosemans JM. Platelet-based coagulation: different populations, different functions. J Thromb Haemost 2013;11(01):2-16

35 Daskalakis M, Colucci G, Keller P, et al. Decreased generation of procoagulant platelets detected by flow cytometric analysis in patients with bleeding diathesis. Cytometry B Clin Cytom 2014;86 (06):397-409

36 Alberio L, Safa O, Clemetson KJ, Esmon CT, Dale GL. Surface expression and functional characterization of alpha-granule factor V in human platelets: effects of ionophore A23187, thrombin, collagen, and convulxin. Blood 2000;95(05):1694-1702

37 Dale GL, Friese P, Batar P, et al. Stimulated platelets use serotonin to enhance their retention of procoagulant proteins on the cell surface. Nature 2002;415(6868):175-179

38 Svendsen MS, Rojkjaer R, Kristensen AT, Salado-Jimena JA, Kjalke $\mathrm{M}$, Johansson PI. Impairment of the hemostatic potential of platelets during storage as evaluated by flow cytometry, thrombin generation, and thrombelastography under conditions promoting formation of coated platelets. Transfusion 2007;47(11): 2057-2065

39 Charania R, Smith J, Vesely SK, Dale GL, Holter J. Quantitation of coated platelet potential during collection, storage, and transfusion of apheresis platelets. Transfusion 2011;51(12):2690-2694

40 Gerber B, Alberio L, Rochat S, et al. Safety and efficacy of cryopreserved autologous platelet concentrates in HLA-alloimmunized patients with hematologic malignancies. Transfusion 2016;56(10):2426-2437
41 Ponschab M, Schöchl H, Gabriel C, et al. Haemostatic profile of reconstituted blood in a proposed 1:1:1 ratio of packed red blood cells, platelet concentrate and four different plasma preparations. Anaesthesia 2015;70(05):528-536

42 Ågren A, Edgren G, Ambrosio D, Gryfelt G, Östlund A, Wikman A. Haemostasis monitored in stored red blood cells, plasma and platelet concentrates in the proportion of 4: 4: 1 diluted with crystalloids and colloids. Blood Coagul Fibrinolysis 2016;27(03): 334-339

43 Labrie A, Marshall A, Bedi H, Maurer-Spurej E. Characterization of platelet concentrates using dynamic light scattering. Transfus Med Hemother 2013;40(02):93-100

44 Maurer-Spurej E, Labrie A, Pittendreigh C, et al. Platelet quality measured with dynamic light scattering correlates with transfusion outcome in hematologic malignancies. Transfusion 2009;49 (11):2276-2284

45 Leitner GC, List J, Horvath M, Eichelberger B, Panzer S, JilmaStohlawetz P. Additive solutions differentially affect metabolic and functional parameters of platelet concentrates. Vox Sang 2016;110(01):20-26

46 Prudent M, Sonego G, Abonnenc M, Tissot J-D, Lion N. LC-MS/MS analysis and comparison of oxidative damages on peptides induced by pathogen reduction technologies for platelets. J Am Soc Mass Spectrom 2014;25(04):651-661

47 Johnson L, Marks D. Treatment of platelet concentrates with the mirasol pathogen inactivation system modulates platelet oxidative stress and NF-KB activation. Transfus Med Hemother 2015;42 (03):167-173

48 Green SM, Padula MP, Marks DC, Johnson L. The lipid composition of platelets and the impact of storage: an overview. Transfus Med Rev 2020;34(02):108-116

49 Lion N, Tissot JD, Prudent M. Is proteomics still knockin' on the hematological door? Proteomics Clin Appl 2016;10(08):765-766

50 García A, Prabhakar S, Brock CJ, et al. Extensive analysis of the human platelet proteome by two-dimensional gel electrophoresis and mass spectrometry. Proteomics 2004;4(03):656-668

51 Qureshi AH, Chaoji V, Maiguel D, et al. Proteomic and phosphoproteomic profile of human platelets in basal, resting state: insights into integrin signaling. PLoS One 2009;4(10):e7627

52 Burkhart JM, Vaudel M, Gambaryan S, et al. The first comprehensive and quantitative analysis of human platelet protein composition allows the comparative analysis of structural and functional pathways. Blood 2012;120(15):e73-e82

53 Salunkhe V, De Cuyper IM, Papadopoulos P, et al. A comprehensive proteomics study on platelet concentrates: platelet proteome, storage time and Mirasol pathogen reduction technology. Platelets 2019;30(03):368-379

54 Sonego G, Abonnenc M, Crettaz D, Lion N, Tissot JD, Prudent M. Irreversible oxidations of platelet proteins after riboflavin-UVB pathogen inactivation. Transfus Clin Biol 2020;27(01):36-42

55 Aloui C, Barlier C, Claverol S, et al. Differential protein expression of blood platelet components associated with adverse transfusion reactions. J Proteomics 2019;194:25-36

56 Prudent M, Crettaz D, Delobel J, Tissot J-D, Lion N. Proteomic analysis of Intercept-treated platelets. J Proteomics 2012;76(Spec No):316-328

57 García A, Prabhakar S, Hughan S, et al. Differential proteome analysis of TRAP-activated platelets: involvement of DOK-2 and phosphorylation of RGS proteins. Blood 2004;103(06):2088-2095

58 Beck F, Geiger J, Gambaryan S, et al. Temporal quantitative phosphoproteomics of ADP stimulation reveals novel central nodes in platelet activation and inhibition. Blood 2017;129(02):e1-e12

59 Schubert P, Coupland D, Culibrk B, Goodrich RP, Devine DV. Riboflavin and ultraviolet light treatment of platelets triggers p38MAPK signaling: inhibition significantly improves in vitro platelet quality after pathogen reduction treatment. Transfusion 2013;53(12):3164-3173 
60 Sonego G, Abonnenc M, Tissot J-D, Prudent M, Lion N. Redox proteomics and platelet activation: understanding the redox proteome to improve platelet quality for transfusion. Int $\mathrm{J}$ Mol Sci 2017;18(02):1-22

61 Verhaar R, Dekkers DWC, De Cuyper IM, Ginsberg MH, de Korte D, Verhoeven AJ. UV-C irradiation disrupts platelet surface disulfide bonds and activates the platelet integrin alphallbbeta3. Blood 2008;112(13):4935-4939

62 Sonego G, Le T-TM, Crettaz D, Abonnenc M, Tissot JD, Prudent M. Sulfenylome analysis of pathogen-inactivated platelets reveals the role of cysteine oxidation in integrin allbbIII-mediated platelet activation. Submitted

63 Cardigan R, Turner C, Harrison P. Current methods of assessing platelet function: relevance to transfusion medicine. Vox Sang 2005;88(03):153-163

64 Saris A, Kreuger AL, Ten Brinke A, et al. The quality of platelet concentrates related to corrected count increment: linking in vitro to in vivo. Transfusion 2019;59(02):697-706

65 Heddle NM, Arnold DM, Webert KE. Time to rethink clinically important outcomes in platelet transfusion trials. Transfusion 2011;51(02):430-434

66 Slichter SJ. Relationship between platelet count and bleeding risk in thrombocytopenic patients. Transfus Med Rev 2004;18(03):153-167

67 Opheim EN, Apelseth TO, Stanworth SJ, Eide GE, Hervig T. Thromboelastography may predict risk of grade 2 bleeding in thrombocytopenic patients. Vox Sang 2017;112(06):578-585

68 Heddle NM, Cardoso M, van der Meer PF. Revisiting study design and methodology for pathogen reduced platelet transfusions: a round table discussion. Transfusion 2020;60(07):1604-1611
69 Kuruvilla DJ, Widness JA, Nalbant D, et al. Estimation of adult and neonatal RBC lifespans in anemic neonates using RBCs labeled at several discrete biotin densities. Pediatr Res 2017;81(06):905-910

70 Mock DM, Lankford GL, Widness JA, Burmeister LF, Kahn D, Strauss RG. Measurement of circulating red cell volume using biotin-labeled red cells: validation against $51 \mathrm{Cr}$-labeled red cells. Transfusion 1999;39(02):149-155

71 Mock DM, Widness JA, Veng-Pedersen P, et al. Measurement of posttransfusion red cell survival with the biotin label. Transfus Med Rev 2014;28(03):114-125

72 Alberio L, Dale GL. Platelet biotinylation for monitoring in vivo survival and cellular function. Platelets 1997;8(06):373-378

73 Stohlawetz P, Horvath M, Pernerstorfer T, et al. Effects of nitric oxide on platelet activation during plateletpheresis and in vivo tracking of biotinylated platelets in humans. Transfusion 1999;39 (05):506-514

74 Ravanat C, Heim V, Pongerard A, Dupuis A, Gachet C. Les plaquettes humaines marquées à différentes densités de biotine: une approche prometteuse pour la mesure simultanée de la survie de plaquettes in vivo dans des études cliniques. Transfus Clin Biol 2018;25(04):323-324

75 de Bruin S, van de Weerdt EK, Sijbrands D, et al. Biotinylation of platelets for transfusion purposes a novel method to label platelets in a closed system. Transfusion 2019;59(09):2964-2973

76 Spitalnik SL, Triulzi D, Devine DV, et al; State of the Science in Transfusion Medicine Working Groups. 2015 proceedings of the National Heart, Lung, and Blood Institute's State of the Science in Transfusion Medicine symposium. Transfusion 2015;55(09): 2282-2290 